\title{
Patients with Heart Failure During and After Inpatient Cardiac Rehabilitation
}

This article was published in the following Dove Press journal:

Vascular Health and Risk Management

\author{
Juliane Schürmann' \\ Frank Noack (D) ${ }^{2,3}$ \\ Steffi Bethge ${ }^{4}$ \\ Viktoria Heinze ${ }^{4}$ \\ Axel Schlitt ${ }^{4,5}$ \\ 'Department of Cardiology and \\ Pulmonology AMEOS Clinic Bernburg, \\ Bernburg, Germany; ${ }^{2}$ Department of \\ Emergency Medicine, University Clinic \\ Halle-Saale, Halle, Germany; \\ ${ }^{3}$ Department of Medicine I, University \\ Clinic Halle-Saale, Halle, Germany; \\ ${ }^{4}$ Paracelsus-Harz-Clinic Bad Suderode, \\ Quedlinburg, Germany; ${ }^{5}$ Medical Faculty, \\ Martin-Luther-University Halle- \\ Wittenberg, Halle, Germany
}

Correspondence: Juliane Schürmann

Department of Cardiology and Pulmonology AMEOS Clinic, Bernburg, 06406, Germany

Tel +49 347I 34I504

Fax +49 347। 342053

Email jsch.med@bernburg.ameos.de
Background: Heart failure is the third most fatal disease in Germany and generates considerable treatment costs. The multimodal program of inpatient rehabilitation can improve the symptoms and prognosis of these patients. At the present time, however, only few data are available on the effectiveness of rehabilitation for heart failure patients.

Methods: After receiving study approval from the ethics committee of the Saxony-Anhalt Medical Association, 200 patients with a primary or secondary diagnosis of heart failure were prospectively included in the study at Paracelsus-Harz-Clinic Bad Suderode, Quedlinburg, Germany. Baseline parameters such as age, gender, and BMI were documented. Outcome variables included NYHA classifications, quality of life, and mortality. For followup, the patients were contacted again by mail or phone after three and 12 months and, data on symptoms and serious events were recorded.

Results: The proportion of patients with a highly reduced ejection fraction (HFrEF) was $13.5 \%$, with a midrange reduced ejection fraction (HFmrEF) 33\%, and with preserved ejection fraction (HFpEF) 53.5\%. The mean age was $64 \pm 11.9$ years, the proportion of women $24.1 \%$. The effects of rehabilitation were documented by low overall mortality (no patient died during the stay, only $4 \%$ of the patients died in the 12-month follow-up) and an improvement in NYHA classification during and after the inpatient rehabilitation.

Conclusion: This monocentric study showed effects both for symptoms (improvement in NYHA classifications) and prognosis (overall mortality) after rehabilitation. These data reflect the effectiveness of multimodal rehabilitation and underscore the need for rehabilitation in patients diagnosed with heart failure after an acute event and hospital stay or who present with chronic deterioration.

Keywords: heart failure, cardiac rehabilitation, inpatient rehabilitation

\section{Introduction}

Heart failure (HF) is a chronic and progressive disease that affects millions of people worldwide. In these patients, performance is reduced owing to an insufficient supply of oxygen-saturated blood to the body. HF represents a serious clinical syndrome, which can become manifest in dyspnea, cyanosis, edema and reduced performance. ${ }^{1}$ Mortality is high $^{2}$ and $\mathrm{HF}$ is associated with expensive medical care. ${ }^{3}$ In Germany, chronic HF is the third most common cause of death among men and the fourth most common among women. The current prevalence of HF in this country is $2-3.9 \%$, with an annual increase of 400,000 patients. The older the patients are, the higher the risk of illness becomes. ${ }^{1}$ Owing to the increasing aging of the population and the increased chances of survival for people with coronary heart disease, cardiomyopathy, or secondary myocardial diseases, the rate of 
chronic HF can also be expected to rise in the next decades, too. ${ }^{4}$ Disease progression is often accompanied by acute life-threatening decompensations and hospitalization in the course of the illness. This, in turn, results in damage to the heart muscle and promotes the progression of the disease. $^{5}$

The multimodal program of inpatient rehabilitation can improve symptoms and prognosis in these patients, and also help prevent decompensations. ${ }^{3}$ Optimization of the pharmacotherapy initiated during a hospital stay after an acute event, implementation of standardized training courses, individualized endurance and coordination training, and psychological support with help for professional reintegration constitute core components of the rehabilitation program for HF patients. ${ }^{6}$ At the present time, however, only few data are available on the effectiveness of rehabilitation for these individuals. Hardly any studies at all have addressed the issue of inpatient rehabilitation with heart failure at all. ${ }^{7}$

The goal of this work is to evaluate the treatment of patients with HF during and after inpatient rehabilitation.

\section{Patients and Methods}

After receiving approval from the ethics committee of the Saxony-Anhalt Medical Association, 200 consecutive patients with a main or secondary diagnosis of HF were prospectively included in this study conducted at Paracelsus Harz Clinic, Bad Suderode, Quedlinburg, Germany, after giving written informed consent. Patients were recruited from September 2016 to July 2017. Our study complies with the Declaration of Helsinki.

General parameters such as age, gender, body mass index (BMI), social status, and left ventricular ejection fraction (LVEF) were collected. Outcome variables included NYHA class, re-hospitalization, and mortality before and after discharge. Furthermore, quality of life (SF12- questionnaire), depression, and anxiety questionnaires (HADS-D- questionnaires) were evaluated.

We divided the patients into three groups based on the left ventricular ejection fraction (LVEF), according to the AHA guideline from 2016. Patients with a current LVEF of less than $40 \%$ were assigned to the HFrEF group (Heart Failure with reduced Ejection Fraction). Patients with a LVEF above or equal to $50 \%$ represented the HFpEF group (Heart Failure with preserved ejection fraction). Those patients whose LVEF was between $40 \%$ and $49 \%$ were assigned to the HFmrEF group (Heart Failure with midrange Ejection Fraction). ${ }^{8}$
For the follow-up, the patients were contacted again by mail or phone after 3 and 12 months. Data on symptoms, serious events, and current medication were collected, and, again, questionnaires for monitoring quality of life, depression, and anxiety were completed.

In the SF-12 test, in order to record quality of life, for example, the patients were asked whether they were still able to take care of their everyday affairs or make social contacts, as they were in the past. They could grade their answers between 0 , nothing is possible, and 3, having no restrictions. ${ }^{9}$ In the HADS-D test, there were two times seven questions, each to record the current level of anxiety and depression in the patient. For example, patients were asked whether they suddenly became anxious because of their illness or whether they were already worried upon waking up. They could answer yes or no. ${ }^{10}$ When classifying the NYHA classification, the patients had to state subjectively whether they have no dyspnea (NYHA I), dyspnea during heavy activity (NYHA II), dyspnea during light activity (NYHA III) or rest dyspnea (NYHA IV). ${ }^{11}$

Standard rehabilitation for patients with HF in the Paracelsus-Harz Clinic consists of medical history, laboratory tests, and electrocardiogram (ECG) at admission and cycle ergometry and echocardiography the day after admission. Depending on physical fitness, severity of primary disease, comorbidities, and other confounders, the exercise and rehabilitation program is set up the day after admission. Patients in good clinical condition participate 6 days a week in heart rate-monitored, 30-minute cycle ergometry training. Moreover, these patients participated in Nordic Walking, medical training therapy, intensive gymnastic/exercises, and other activities. Patients who are less physically fit participate in group exercises, chair exercises, and personal training sessions. All patients, independent of their physical fitness, attend seminars and lectures as part of the three-week rehabilitation program. Accordingly after classification of our study patients, all collected parameters were compared among these three HF groups.

The aim of these tests was to determine whether there are any correlations between the different HF groups with regard to the parameters surveyed, as well as the advantages and disadvantages of treatment.

\section{Statistical Methods}

Continuous variables are reported as mean \pm standard deviation (SD) and categorical variables as percentage. Chi-squared test and one-factor ANOVA test were used to compare continuous, skewed, and categorical variables, 
respectively. A p-value $<0.05$ was considered statistically significant. All computations were carried out with SPSS software (version 25; IBM Corporation, Armonk, NY, USA).

\section{Results}

The mean patient age was $64.7 \pm 11.9$ years, $75.9 \%$ were male, and mean BMI was $29.0 \pm 5.2 \mathrm{~kg} / \mathrm{m}^{2}$. Mean length of inpatient rehabilitation was $27.7 \pm 3.5$ days. Furthermore, $1.5 \%$ had no educational qualifications and $11.8 \%$ had a university degree. Among the study participants, 33.8\% were still in gainful employment and 56.8\% had already retired. German pension insurance covered costs for $18.2 \%$ and health insurance for $51.8 \%$ of the patients. Arterial hypertension was reported in $79.9 \%$ of all patients at admission. Other cardiovascular risk factors included active smoking in $29.1 \%$ and diabetes in $41.7 \%$. Further comorbidities are presented in Table 1. The proportion of patients with a highly reduced ejection fraction (HFrEF) was $13.5 \%$, with a midrange reduced ejection fraction (HFmrEF) 33\%, and with preserved ejection fraction (HFpEF) 53.3\%. Follow-up information was obtained from $90.5 \%$ of the patients after 12 months.

Figure 1 compares the vital parameters of the patients between inpatient admission and discharge. Systolic blood pressure dropped from an average of $136 \mathrm{mmHg}$ to 132 $\mathrm{mmHg}$ and diastolic blood pressure fell from $80 \mathrm{mmHg}$ to 78 $\mathrm{mmHg}$. The heart rate decreased from 76 to $73 \mathrm{bpm}$ during the inpatient stay. The patients lost an average of $0.7 \mathrm{~kg}$ in weight, which resulted in a drop in the BMI from 29.0 to $28.8 \mathrm{~kg} / \mathrm{m}^{2}$.

The effects of the rehabilitation were documented by an improvement in the NYHA classification during and partly after the inpatient rehabilitation (Figure 2). The share of patients with NYHA I class rose from $19.6 \%$ at admission to $24.8 \%$ at discharge and was even $27.3 \%$ after 1 year. NYHA class II rose from $35.2 \%$ at admission to $54.1 \%$ at discharge and was $44.2 \%$ after 1 year. NYHA class III fell from $44.2 \%$ at admission to $19.6 \%$ at discharge and was still $25.4 \%$ after 1 year. NYHA class IV was $1 \%$ at admission, $1.5 \%$ at discharge, and $3 \%$ after 1 year.

Neither HADS-D anxiety nor HADS-D depression scores had changed significantly between the time of admission and discharge as compared to the types of HF. The overall value of the anxiety symptoms was slightly below the middle of the range (score 8-11) both at admission and upon released from the hospital. This trend and the lack of statistical significance were also observed in the follow-up surveys (Figure 3A and B).
Table I Patient Characteristics

\begin{tabular}{|c|c|}
\hline Variables & $\mathbf{N}=\mathbf{2 0 0}$ \\
\hline \multicolumn{2}{|l|}{ Sociodemographic data } \\
\hline Age (years) & $64.7 \pm 11.9$ \\
\hline Female sex (\%) & 24.1 \\
\hline Male sex (\%) & 75.9 \\
\hline Weight (kg) & $86.2 \pm 17.1$ \\
\hline BMI $\left(\mathrm{kg} / \mathrm{m}^{2}\right)$ & $29 \pm 5.2$ \\
\hline Length of inpatient rehabilitation (days) & $21.7 \pm 3.5$ \\
\hline \multicolumn{2}{|l|}{ Patient history/comorbidities } \\
\hline Active smoking (\%) & 29.1 \\
\hline Hypertension (\%) & 79.9 \\
\hline Diabetes (\%) & 41.7 \\
\hline COPD (\%) & 8 \\
\hline Dyslipoproteinemia (\%) & 69.8 \\
\hline Renal insufficiency (\%) & 16.1 \\
\hline Atrial fibrillation (\%) & 23.1 \\
\hline Coronary heart disease (\%) & 45.7 \\
\hline Acute myocardial infarction (\%) & 66.3 \\
\hline Pulmonary embolism (\%) & 4.5 \\
\hline \multicolumn{2}{|l|}{ Heart Failure groups } \\
\hline HFrEF (\%) & 13.5 \\
\hline HFmrEF (\%) & 33 \\
\hline HFpEF (\%) & 53.5 \\
\hline \multicolumn{2}{|l|}{ Cost bearer } \\
\hline German pension insurance (\%) & 48.2 \\
\hline Health insurance (\%) & 51.8 \\
\hline \multicolumn{2}{|l|}{ Graduation } \\
\hline No graduation (\%) & 1.5 \\
\hline Apprenticeship (\%) & 86.7 \\
\hline Graduate (\%) & 11.8 \\
\hline \multicolumn{2}{|l|}{ Employment } \\
\hline Employed (\%) & 33.8 \\
\hline Unemployed (\%) & 9 \\
\hline Retired (\%) & 56.8 \\
\hline
\end{tabular}

Note: Categorial variables are presented in percent; continuous normally distributed variables as mean \pm standard deviation at admission.

Abbreviations: HFrEF, highly reduced ejection fraction; HFmrEF, midrange reduced ejection fraction; HFpEF, preserved ejection fraction.

The questionnaires on the quality of life of the patients (SF-12) also did not differ significantly between the groups and during the course of the study. The values of the physical summation scale as a whole are below the average total value of 50 per summation scale. The psychological summation scale shows an increase by approximately three points, which indicates a slight improvement in the psychological state. An analogous dynamic can be found in the evaluation of the SF-12 values after 3 and 12 months (Figure 4A and B). 


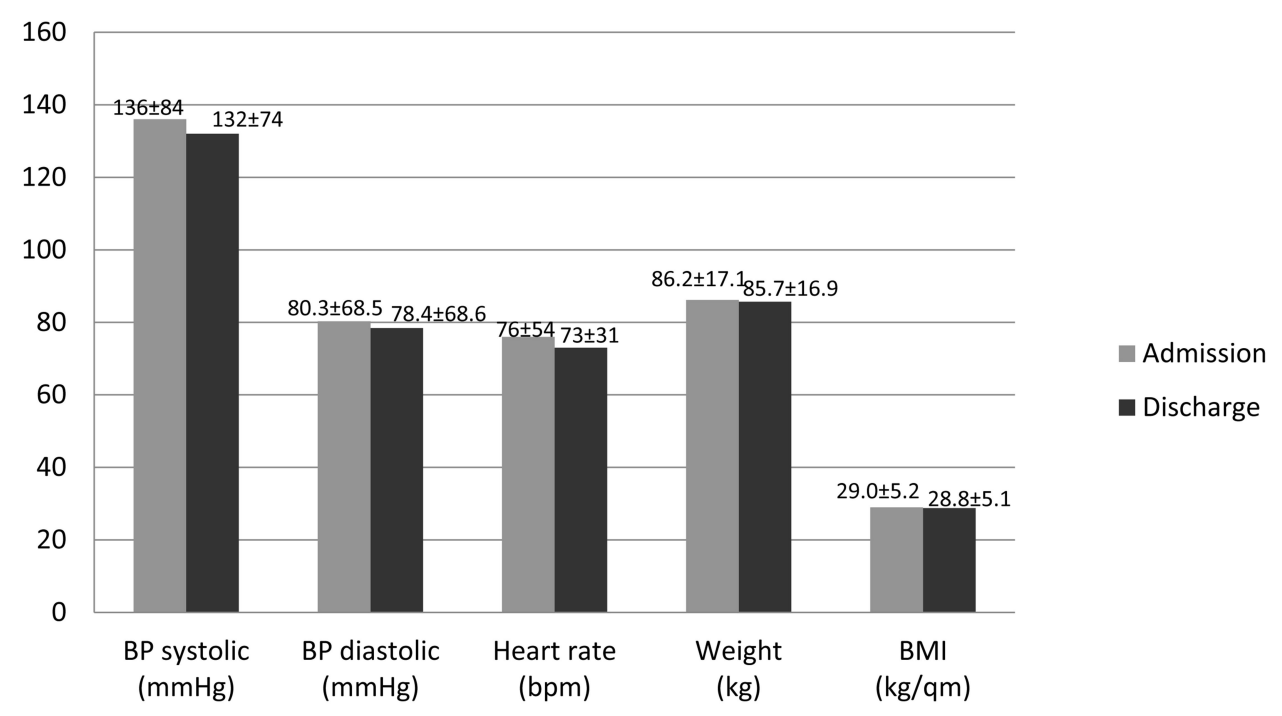

Figure I Development of vital parameters between admission and discharge.

NYHAI $\square$ NYHA II NYHA III $\square$ NYHA IV

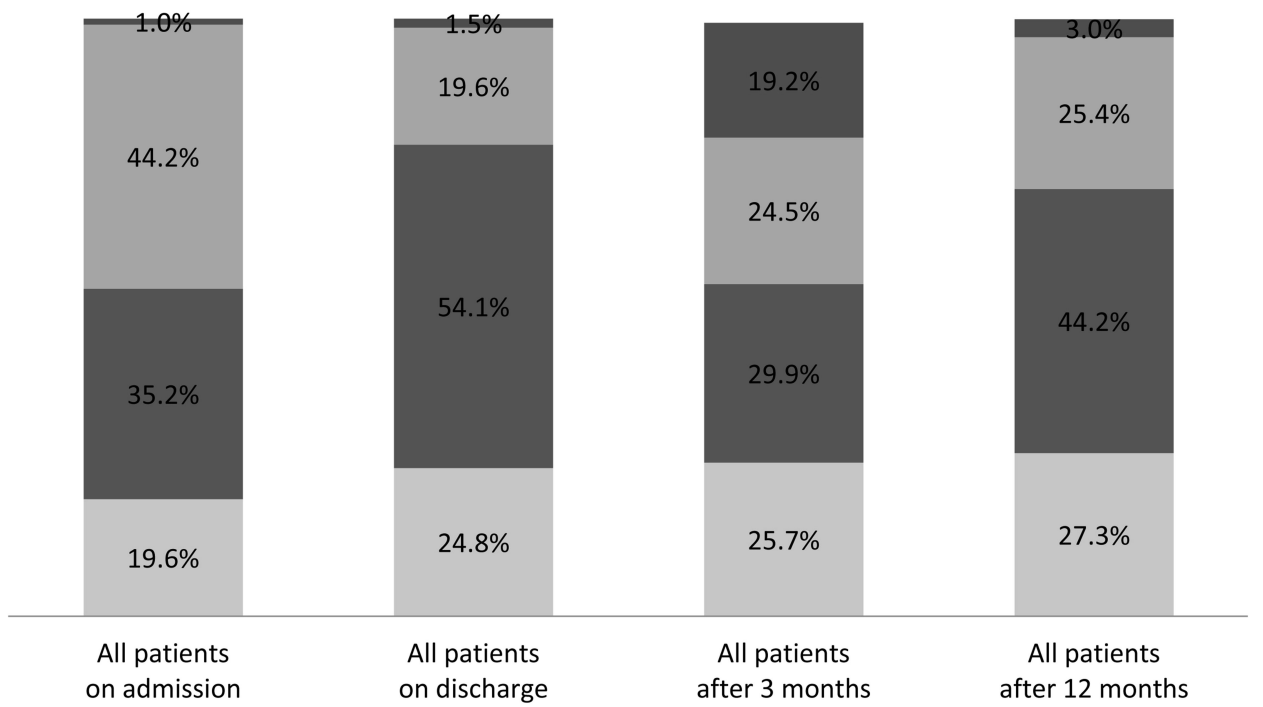

Figure 2 NYHA-classes during study course.

\section{Drug Treatment}

Drug treatment is outlined in Table 2. The drugs typically used for HF patients ${ }^{3}$ are beta-blockers, ACE inhibitors, angiotensin-receptor blockers (ARB), mineralocorticoid receptor antagonists (MRA), Ivabradine, and sacubitril/ valsartan. Their use during and after inpatient rehabilitation is shown in Figure 5. At admission, $52.8 \%$ of the patients were using ACE inhibitors. Here, a change was observed during the course of the study, with $45.2 \%$ taking ACE inhibitors at discharge and $37.6 \%$ after 12 months. The use of beta-blockers was stable at $88.4 \%$ at admission and discharge and decreased to $87.9 \%$ after 1 year. At admission, $28.1 \%$ of the patients were taking ARBs. ARB use rose at discharge to $39.4 \%$ and to $40 \%$ after 1 year. The use of MRAs was nearly stable: $27.5 \%$ at admission and $27.9 \%$ at discharge. This rate changed during the study follow-up period to $24.4 \%$ after 12 months. The use of Ivabradine rose from $1.5 \%$ at admission to $6.6 \%$ at discharge and fell to $2.4 \%$ after 1 year. Medication with sacubitril/valsartan rose continuously from $1.5 \%$ at admission to $2.5 \%$ at discharge and to $5.5 \%$ after 1 year. 


\section{A HADS-D, anxiety score}

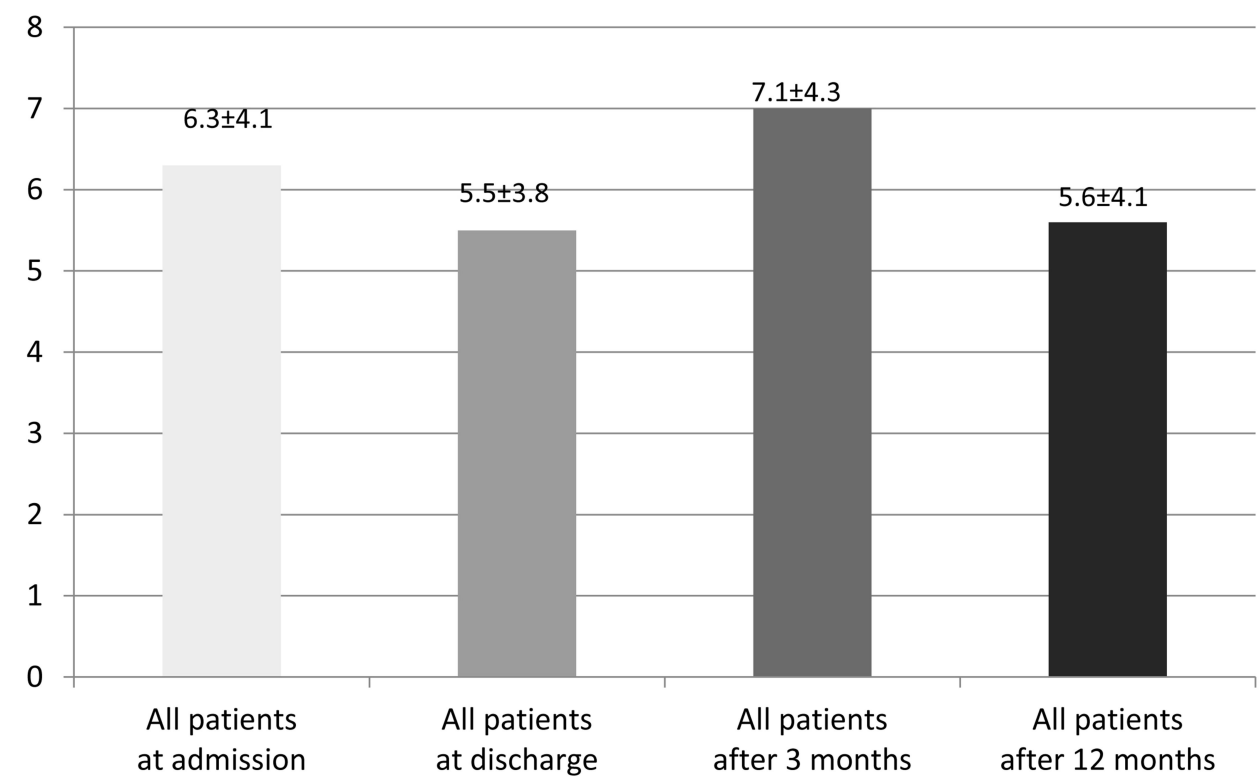

\section{B HADS-D, depression score}

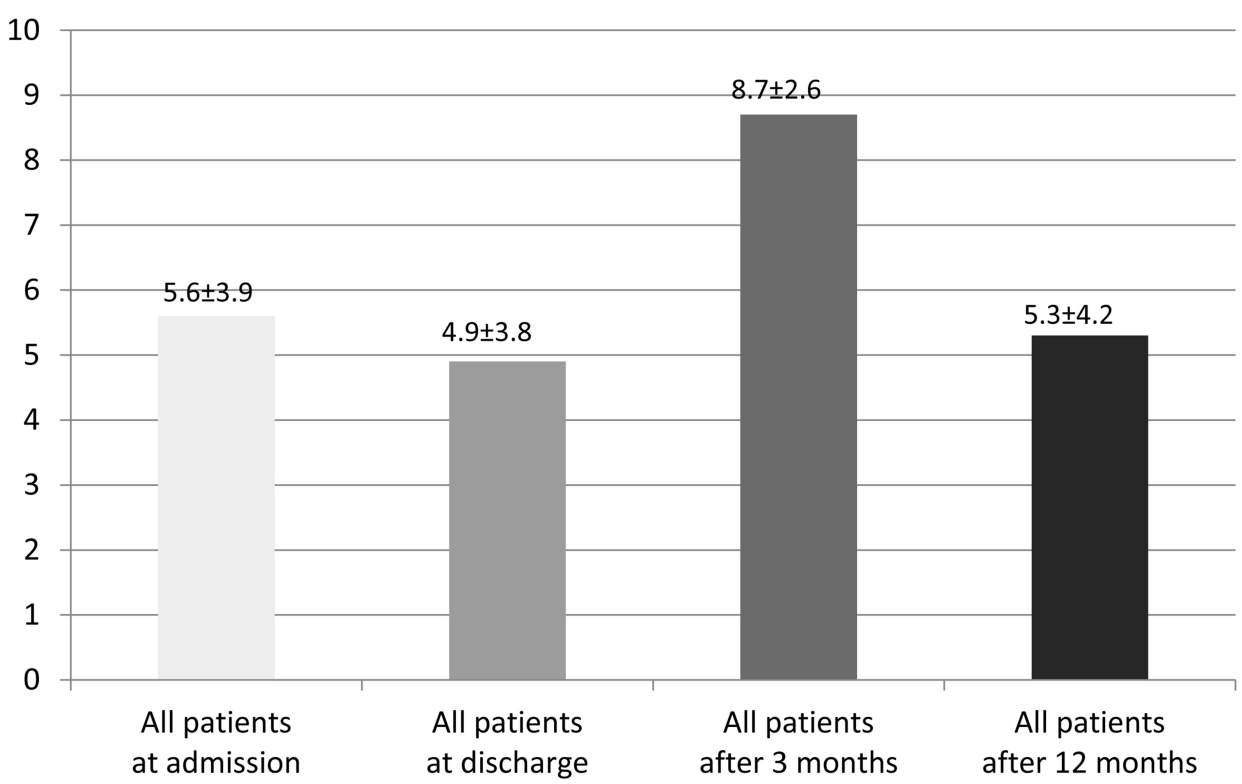

Figure 3 (A) HDS-D, anxiety score. (B) HADS-D, depression score.

In the 200 participating patients, HF medication was changed in 79 patients by the 3-month -follow-up, which corresponds to $39.5 \%$. Up to the 12 -month follow-up, medication was changed in a total of 97 patients, which corresponds to $48.5 \%$. In the end, a physician had prescribed all changes in HF medication. In 19 cases a patient requested such a change, but this was discussed with the physician who continued to treat the patient. None of the patients reported that they had completely independently changed their therapy regimen.

\section{Adverse Events}

Adverse events are outlined in Figure 6, differentiated according to HF type. During the inpatient stay, a total of eight patients needed to be transferred owing to an acute event, which corresponds to $4 \%$. Just under two-thirds of these were cardiac events and one-third non-cardiac. Among these patients, thoracic pain prompted the transfer in two cases. Due to thoracic pain, one woman needed to be transferred to another hospital, an acute myocardial 


\section{A SF-12 Physical summation scale}

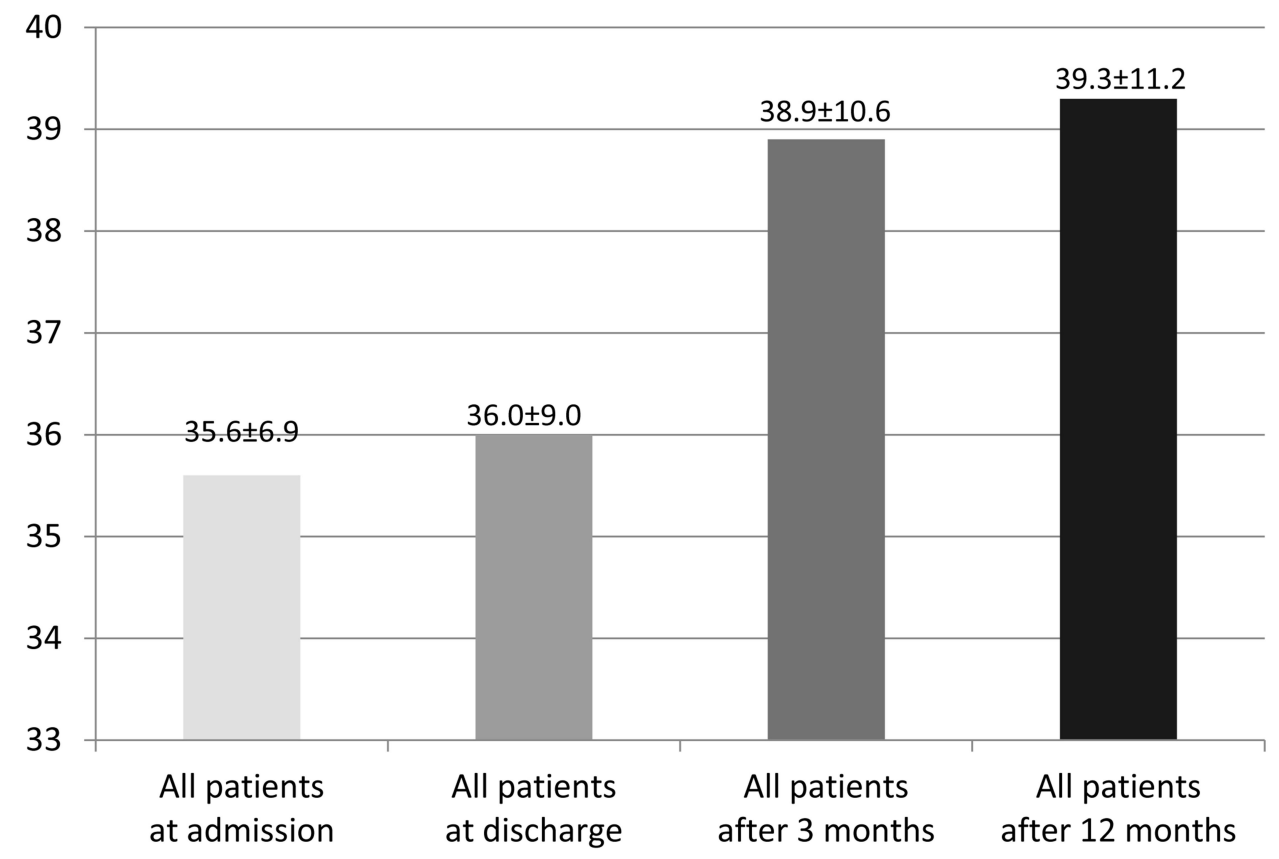

\section{B SF-12 Psychologic summation scale}

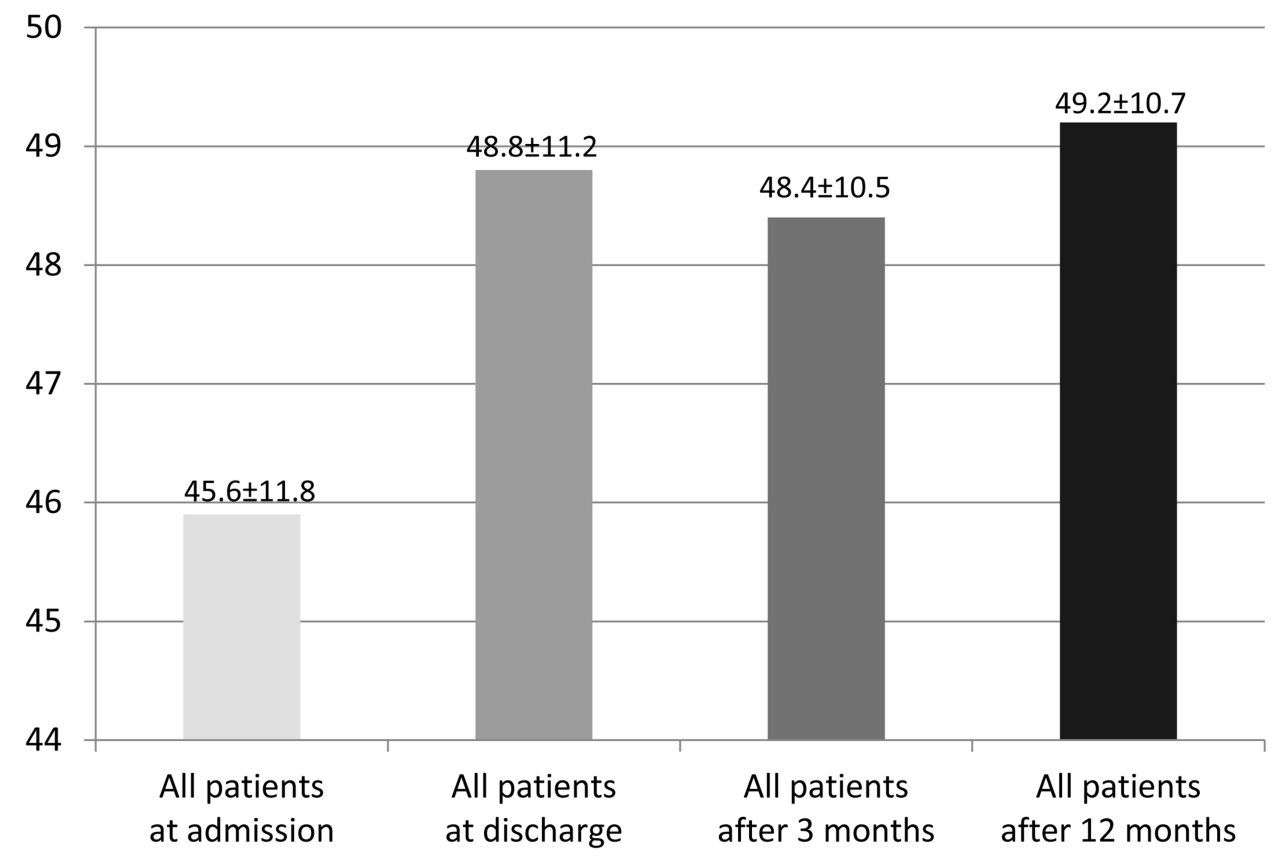

Figure 4 (A) SF-12: Physical summation scale. (B) SF-12: Psychologic summation scale.

infarction could be excluded; a tachycardic event presented in a patient with a known absolute arrhythmia; and, after an acute myocardial infarction, emergency transfer to the heart center in Leipzig was required for yet another patient. One man developed dyspnea, thoracic pain, and cyanosis. Shortly after the transfer, he died in the emergency room before receiving further diagnostic tests and therapy. Two other patients suffered from nosebleed, which could only be stopped in a special clinic.

After evaluating the twelve-month follow-up questionnaires, 64 patients had been rehospitalized: 33 cases were of cardiac and 31 cases of noncardiac 
Table 2 Drug Treatment During Study Course

\begin{tabular}{|l|l|l|l|l|}
\hline Drug, \% & Admission & Discharge & After 3 Months & After I2 Months \\
\hline Ca-antagonists & 24.1 & 33.8 & 28.8 & 29.7 \\
Beta-blockers & 88.4 & 88.4 & 87.3 & 87.9 \\
Ivabradine & 1.5 & 6.6 & 1.8 & 2.4 \\
Amiodaron & 4.5 & 2.5 & 3.0 & 3.0 \\
ACE inhibitors & 52.8 & 45.2 & 42.4 & 37.6 \\
ARBs & 28.1 & 39.4 & 36.9 & 40.0 \\
\hline Sacubitril/valsartan & 1.5 & 2.5 & 5.4 & 5.5 \\
MRA & 27.5 & 27.9 & 26.8 & 24.4 \\
Statins & 75.4 & 83.3 & 79.4 & 76.4 \\
Aspirin & 71.9 & 67.7 & 66.1 & 63.6 \\
\hline P2YI2 inhibitors & 56.3 & 56.6 & 50.0 & 21.2 \\
OACs & 31.2 & 34.3 & 31.5 & 30.9 \\
Insulin & 2.5 & 14.1 & 13.3 & 10.9 \\
OADs & 21.1 & 24.7 & 23.0 & 23.6 \\
\hline
\end{tabular}

Abbreviations: ACE, angiotensin-converting enzyme; ARB, angiotensin-receptor blocker; OAK, oral anticoagulation; OAD, oral antidiabetics; MRA, mineralocorticoid receptor antagonist.

origin. In six cases, cardiac hospitalizations specifically involved interventions due to the coronary heart disease; in 14 cases myocardial decompensation occurred; and in 10 patients, cardiac arrhythmia requiring intervention had developed. Three patients suffered a fatal myocardial infarction. When considering the outcome "death"; however, no patient died during the inpatient stay at the Harz Clinic in Bad Suderode. One patient died shortly after being transferred to another hospital with symptomatic dyspnea, thoracic pain, and cyanosis. Seven further patients died within a year. A total of five non-fatal myocardial infarctions occurred. The drop-out rate was 19 patients.

Figure 7 outlines rehospitalizations owing HF and death of any cause during the course of the study according to HF type.

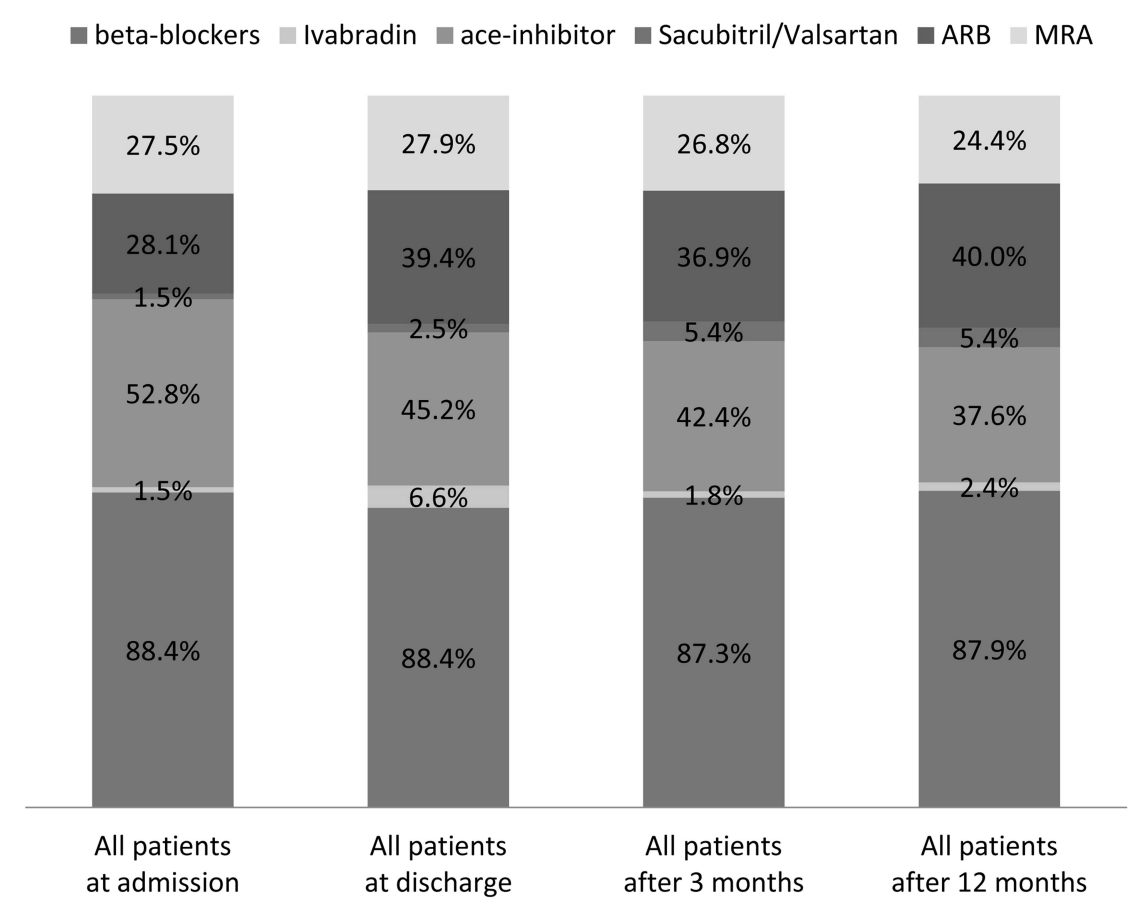

Figure 5 Heart failure medication during study course. 


\section{cardiac cause non-cardiac cause}

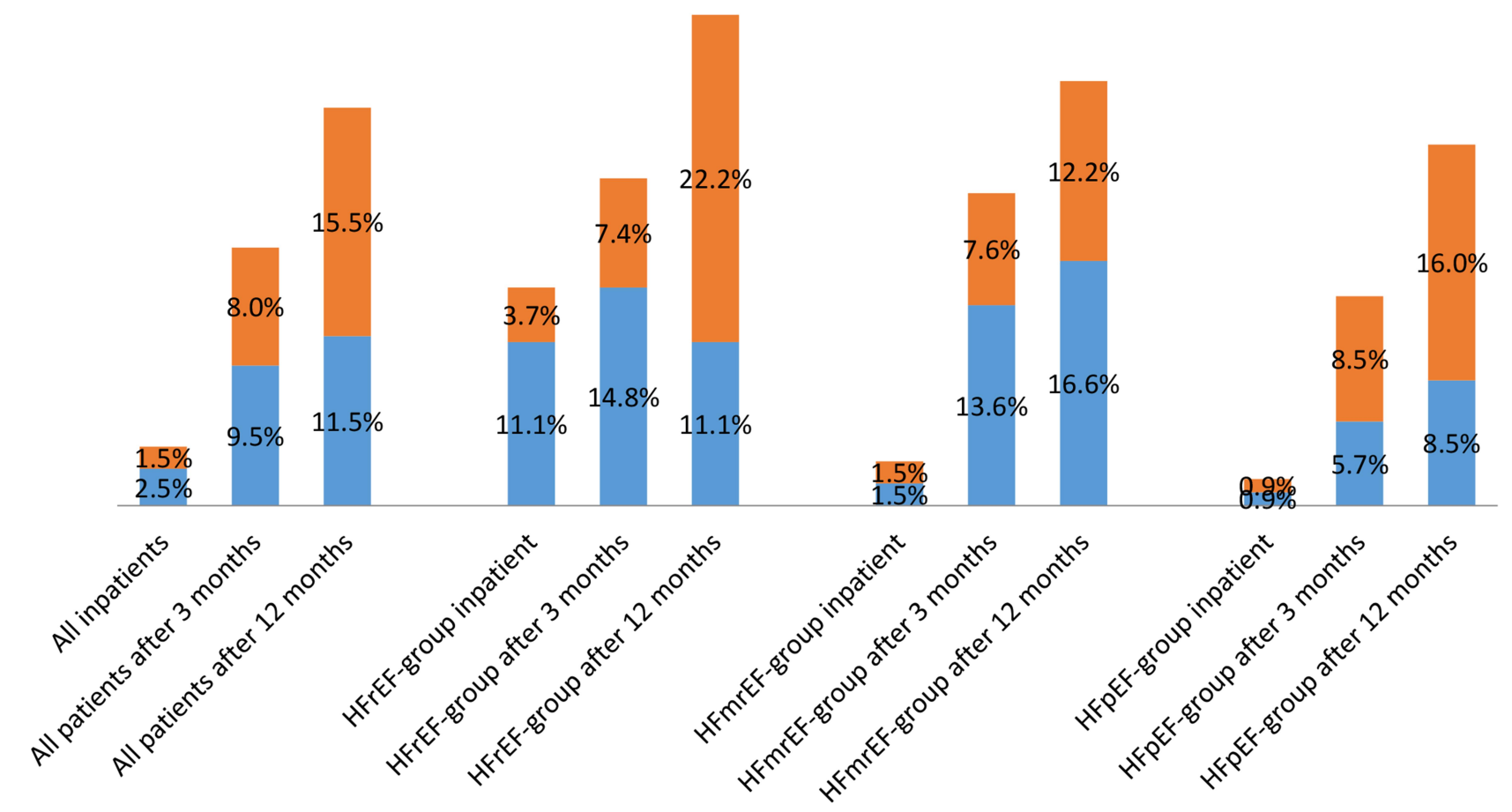

Figure 6 Hospitalizations.

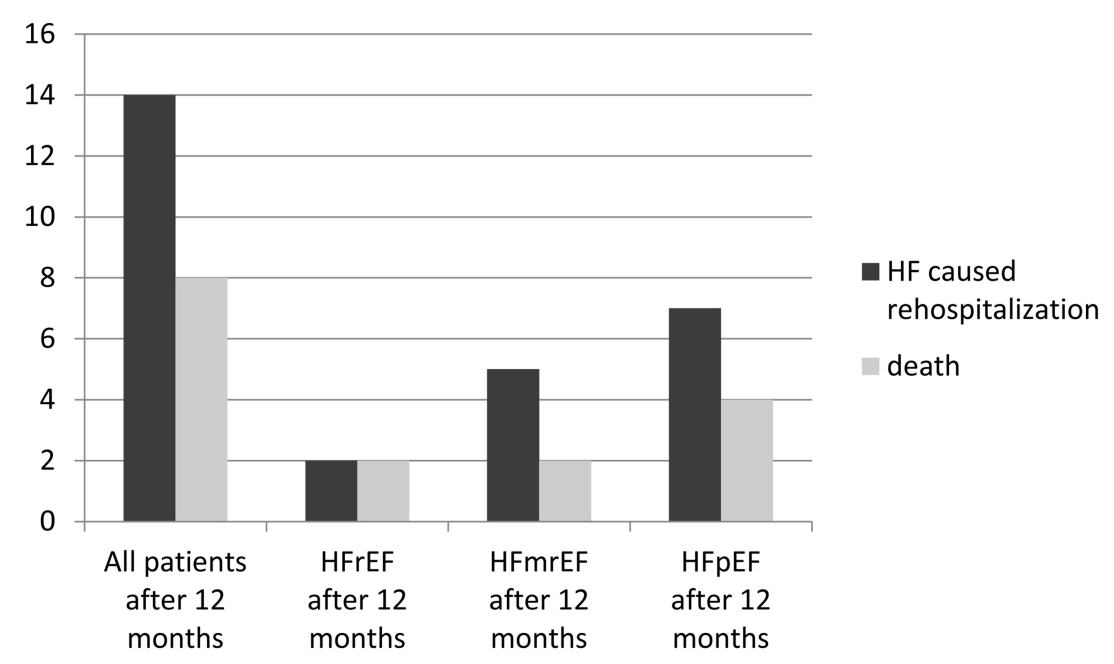

Figure 7 Heart failure caused rehospitalization and death during study course.

\section{Discussion}

HF is a life-threatening disease. After 1 year, $17 \%$ of inpatient patients die and $44 \%$ are rehospitalized because of $\mathrm{HF}^{8}$

In the present study, mortality and numbers of patients rehospitalized because of $\mathrm{HF}$ was surprisingly low at $4 \%$ and $7 \%$, respectively. Since all patients participated in cardiac rehabilitation (CR) as the main inclusion criterion of the study, we hypothesize that patient outcome during the 12month follow-up is influenced by participating in CR.

Previous studies on the effectiveness of CR are very heterogeneous in terms of the number of patients enrolled, the type of randomization, the duration of the follow-up, and the type and duration of the intervention. A recent Cochrane analysis showed that $\mathrm{CR}$ is effective with 
regards to mortality, cardiac events, exercise capacity, and modification of risk factors. ${ }^{12}$

As part of the multimodal rehabilitation, which is typically performed in Germany, exercise has been shown to improve outcome in HF patients.

In 2004, Whellan et al found that physical training can significantly reduce morbidity and probably also mortality in patients with chronic HF. ${ }^{13}$

Finally, since 2009, data have been available from the multicenter, prospective, randomized, and controlled HFACTION study of 2331 patients with an EF $<35 \%$ and receiving the best possible therapy and aggregate care. Initially, no significant decrease in mortality and hospitalization rates were observed - after an observation period lasting 30 months. In this study, the patients trained for the first 3 months according to the trainer's instructions followed by continuing the training at home. The primary endpoint only showed a significant improvement after the data had been adjusted. A connection between the increase in the amount of training and the reduction in mortality and hospitalization was found. In summary, this study was able to show that physical training for HF patients poses no risk and also positively affects and improves physical, psychological, and social restrictions, symptoms, and quality of life. $^{14}$

In general, seriously ill patients can also participate in moderate endurance training, which can also help improve their health and well-being. ${ }^{15}$ One major criticism of the available studies is that, often, no older patients were included, such that the informative value of these studies must be regarded as limited, especially for the group of patients over 65 years of age. The present study considered patients with an average age of 65 .

The ESC guideline for the diagnosis and treatment of acute and chronic HF, which was published in 2016 and was developed with the approval of the Heart Failure Association (HFA) of the ESC, has given a class IA recommendation for physical training - for chronic HF. Nevertheless, prevention and rehabilitation of HF hardly play a role according to the current ESC guideline. ${ }^{16}$

No reliable data are available regarding the therapy and the intensity of physical training at HFmrEF. The present study explicitly compared the endpoints of the HFmrEF group with those of the HFrEF and HFpEF. Accordingly, it became apparent that the HFmrEF group is a separate disease entity with its own characteristics.
Another important effect of CR is improved compliance to drug therapy. During the current study, the use of beta-blockers was stable. However, the use of ARB, Ivabradine, and sacubitril/valsartan rose. Other recent trials in patients with HF show that as disease progresses, compliance with medication decreases. ${ }^{17}$

Multimodal rehabilitation also includes psychosocial care, which is effective in patients with HF (awareness, knowledge and social support).

In the current study, HADS-D and SF-12 showed no significant development of anxiety, depression, and quality of life in the patients.

\section{Limitations}

The study is limited by its monocentric design, which has the potential for under-reporting (e.g., acute myocardial decompensation, and emergency admission to the hospital). Due to missing or some old references, it is unfortunately not really possible to make comparisons with studies by other authors.

\section{Conclusion}

Although limited by its monocentric design, this prospective study showed effects both for symptoms (improvement in NYHA classification) and prognosis (overall mortality) after rehabilitation. These data underline the need for rehabilitation in patients diagnosed with HF after an acute event and hospital stay or who present with chronic deterioration.

In the future, it will be necessary to encourage more and possibly also interventional studies that can provide further data concerning inpatient cardiac rehabilitation.

\section{Acknowledgment}

This study was supported by an unrestricted grant from Novartis ${ }^{\circledR}$, Germany.

\section{Disclosure}

The authors report no conflict of interest in this work.

\section{References}

1. Stork S, Handrock R, Jacob J, et al. Epidemiology of heart failure in Germany: a retrospective database study. Clin Res Cardiol. 2017;106 (11):913-922. doi:10.1007/s00392-017-1137-7

2. Christ M, Stork S, Dorr M, et al.; Heart failure epidemiology 2000-2013: insights from the German federal health monitoring system. Eur J Heart Fail. 2016;18(8):1009-1018. doi:10.1002/ejhf.567

3. Cooperation between the German Medical Association and the National Association of Statutory Health Insurance Physicians at the Medical Center for Qualification in Medicine (ÄZQ). Berlin, Germany. 
4. Freud T, Gerste B, Jencke E, Quality of post-inpatient drug supply for patients with heart failure. Hospital report 2016. (Stuttgart), 2016; 229-249

5. Murad K, Golf DCJ, Morgan TM, et al. Burden of comorbidities and functional and cognitive impairments in elderly patients at the initial diagnosis of heart failure and their impact on total mortality. The cardiovascular health study. JACC Heart Fail. 2015;3(7):542-550. doi:10.1016/j.jchf.2015.03.004

6. Rademacher W, Glatz J, Laugner P, et al. Psychocardiologic rehabilitation-interdisciplinary treatment as a pilot project. J Cardiol. 2019;13:40-48.

7. Medline-research and clinical evidence research from $23 \mathrm{rd}$ of November. 2020.

8. Ponikowski P, Voors AA, Anker SD, et al. 2016 ESC Guidelines for the diagnosis and treatment of acute and chronic heart failure of the European society of cardiology (ESC) developed with the special contribution of the Heart Failure Association (HFA) of the ESC. Eur Heart J. 2016;37(27):2129-2200. doi:10.1093/eurheartj/ehw128

9. Petermann F. Hospital Anxiety and Depression Scale, German Version (HADS-D). J Psychiatry Psychol Psychother. 2011;59(3):251-253.

10. Wirtz MA, Morfeld M, Glaesmer H, Braehler E. Confirmatory test of the scale structure of the SF-12 version 2.0 in a sample representable of the German population. Diagnostica. 2018;64(2):84-96. doi:10.1026/0012-1924/a000194

11. Hunt SA, Abraham WT, Chin MH, et al. Focused update incorporated into ACC/AHA 2005 guidelines for the diagnosis and management of heart failure in adults: a report of the American College of Cardiology Foundation/American Heart Association task force on practice guidelines. Circulation. 2009;119:e391-e479.
12. Schwaab B, Albus C, Waller C, Fritsche K, Gunold H, Haas M. Cochrane analysis in cardiac rehabilitation. Int $J$ Cardiol. 2018;97 (02):117-126.

13. Whellan DJ, Slow LK, Best BK, Kraus WE, Califf RM, O Connor CM. Cardiac rehabilitation and survival in patients with left ventricular systolic dysfunction. Am Heart J. 2004;142:160-166. doi: $10.1067 / \mathrm{mhj} .2001 .115785$

14. O Connor CM, Whellan DJ, Lee KJ, et al.; HF-ACTION Investigations. Efficacy and safety of exercise training in patients with chronic heart failure. HF-ACTION randomized controlled trial. JAMA. 2009;301(14):1439-1450. doi:10.1001/jama.2009.454

15. Tiller D, Russ M, Greiser KH, et al. Prevalence of symptomatic heart failure with reduced and with normal ejection fraction in an elderly general population-the CARLA study. PLoS One. 2013;8(3):e59225. doi:10.1371/journal.pone.0059225

16. Reibis RK, Schlitt A, Glatz J, et al. Rehabilitation in heart failure. Rehabilitation (Stuttg). 2016;55(2):115-27; quiz 128-9. doi:10.1055/ s-0042-103302

17. Holstiege J, Akmatov MK, Steffen A, Bätzing J, Prevalence of heart failure-nationwide trends, regional variations and frequent comorbidities. Central institute for stationary health care in Germany (Ci) supply atlas report- no. 18/19, Berlin. 2018. doi:10.20364/UA-18.09
Vascular Health and Risk Management

\section{Publish your work in this journal}

Vascular Health and Risk Management is an international, peerreviewed journal of therapeutics and risk management, focusing on concise rapid reporting of clinical studies on the processes involved in the maintenance of vascular health; the monitoring, prevention and treatment of vascular disease and its sequelae; and the involvement of metabolic disorders, particularly diabetes. This journal is indexed on PubMed Central and MedLine. The manuscript management system is completely online and includes a very quick and fair peerreview system, which is all easy to use. Visit http://www.dovepress. com/testimonials.php to read real quotes from published authors. 